\title{
Analysis model of logistics supply chain factors in large-scale stacking goods Cheng Bo
}

\author{
Hebei Jiaotong Vocational and Technical College, Hebei Shijiazhuang 050035, China
}

Keywords: logistics route optimization; sales project; improved max min ant

\begin{abstract}
Aiming at the promotion of logistics transportation in the stacking sale goods evacuation, it has been to lack of complete and effective theoretical analysis of this issue. By analyzing the changes of logistics data, the massive stacking sales of goods are taken as the foundation, to carry on the analysis model. The improved max min ant algorithm is used as theoretical basis for the model establishment, the results of commodity sales project profit is taken as the example after logistics supply chain route optimization, to input distribution profit model to make analysis. After logistics route optimization in the special area, the distribution of products is quantified. Experimental results show that the level of market sales, market share rate and changes of profit growth rate are described in proposed model, and the model has higher application value.
\end{abstract}

\section{Introduction}

With the development of market economy, how to realize the fast selling goods has become an important problem of commodity enterprises concerned, the success or failure of sales is the key factor to determine the relevant enterprise survival. Under the conditions of market economy, enterprises who wants to enhance the competition ability and economic benefits, the key process is to solve the problem of the marketing efficiency of product introduction, also is to use the minimum cost of sales and the highest efficiency, to make product to market, and meeting to the needs of the consumers, to achieve the goal of business strategy. The importance of logistics convenience in the field of goods sales gradually increased, commodity sales coordinating with convenient logistics mode, can promote the circulation efficiency of sales of commodities, which has the important role in the commodity distribution [1,2]. Therefore, to find a reasonable method to obtain the relationship between stacking commodity sales and logistics convenience, has become a hot issue in the analysis of enterprise sales management.

In some special area, logistics are extremely inconvenient, the related problems existed in commodity distribution. current selling analysis mode, $[3,4,5,6]$ cannot adapt to the randomness, diversity characteristics of commodity sales brought vy special regional logistics factors, the analysis process is easy to fall into local optimum state, it cannot make full analysis for the logistics factors in the distribution process, without considering the logistics transportation factor in sales in the obtained results, there is a certain deviation, which cannot accurately reflect the profit situation of commodities, there is a big flaw.

\section{Analysis and modeling of logistics convenience based on improved max min ant algorithm}

This paper presents an improved max min ant algorithm to optimize and analyze the logistics supply chain factors in stacking commodity sales. The improved algorithm can avoid the drawbacks of logjam appeared in traditional algorithm, to ensure that the selection and optimization steps goes on smoothly in analysis.

Ensuring that under different logistics condition, the interval of the number of the remaining commodity in stacking commodities is $\left[\tau_{\min }, \tau_{\max }\right], \tau_{\min }$ is used to avoid the standstill of the algorithm, $\tau_{\max }$ is used to constrain the infinite diffusion of algorithm, to reduce the time of information exchange between ants in the analysis algorithm, and generate more information in the frequent path, which can improve the effect of positive feedback of analysis algorithm. The pheromone updating function in algorithm is: 


$$
\tau_{i j}(t+n)=\left\{\begin{array}{l}
\tau_{i j}(t) \text { into contraindication form } t<\tau_{\min } \\
\tau_{i j}(t), \tau_{\min }<\tau_{i j}(t)<\tau_{\max } \\
\tau_{\max }, \tau_{i j}(t)>\tau_{\max }
\end{array}\right.
$$

Among them, $\tau_{i j}(t)$ and $\tau_{i j}(t+n)$ are respectively represented the pheromone concentration of the original and that of completing adjustment, ${ }^{\tau_{\max }}$ is radian pheromone.

If the pheromone on logistics transportation condition only selects one of the cycle optimum or the global optimum, it will appear the optimization stagnation problem, so this paper set ants according to formula (2) to choose the next node:

$$
P_{i j}^{k}(t)=\frac{\left[\tau_{i j}(t)\right]^{\alpha} \cdot\left[\eta_{i j}\right]^{\beta}}{\sum_{l \in N_{i}^{k}}\left[\tau_{i j}(t)\right] \cdot\left[\eta_{i j}\right]^{\beta}}\left(j \in N_{i}^{k}\right)
$$

Pheromone is increased, ants are tend to choose the optimal route solution, in which will appear the stagnate problem. Therefore, to set a ${ }^{P_{\text {best }}}$, it can obtain the prediction value of $\tau_{\text {min }}$. it is made a selection in the elements with different solutions of when ants are in $a v g=n / 2$. from every choice point of logistics transport conditions. According to the formula (3) it can obtain the probability ${ }_{\text {dec }}$ :

$$
P_{d e c}=\frac{\tau_{\max }}{\tau_{\max }+(\operatorname{avg}-1) \cdot \tau_{\min }}
$$

From equation (4) it can get $\tau_{\min }$ value as:

$$
P_{\text {best }}=1, \tau_{\min }=0
$$

Among them, $P_{\text {best }}=1, \tau_{\min }=0$ according to the formula (4), it can obtain $\tau_{\min }$ through known $P_{\text {best }}$ values, so it can choose the optimal effect factors of logistics transportation on sales of bulk commodities.

\section{Commodity profit analysis model influenced by logistics factors}

Through the above analysis method, it can get the effect of logistics factors on stacking commodity sales, to complete the analysis of commodity distribution model in the impact conditions. It needs to analyze the changes of commodity profit under this logistics route, then to make reasonable planning for the commodity profit changes in special region and under different logistics factors. The modeling process is as follows:

Assuming in $\mathrm{T}$ days, in the good distribution center, the demands of product $\mathrm{i}$ is the total demand of product i for all manufacturers. if in the special area, logistics factors have great influence on commodities, goods distribution center under the influence of logistics factor $\mathrm{w}$ issued orders, commercial project completed in advance $\mathrm{L}$ days, and to ensure that the accumulation levels rebound to a maximum inventory levels $S_{i w}$. At $\mathrm{T}$ moment, consumers will order to regional distribution center, then at $\mathrm{T}$ moment, the inventory level is the difference between the maximum inventory levels with the 1 ordering quantity of manufacturers. In a cycle to order, the stock of $\mathrm{T}$ days is the difference of the maximum inventory level with the 2 purchases of manufacturers. The inventory level in remaining $\mathrm{T}$ days is the maximum amount of inventory levels with1 time quantity of manufacturers, to obtain the average inventory level ${ }^{I_{i w}}$ at a fixed logistics factors are:

$$
I_{\text {iw }}=\left\{\int_{-\infty}^{S_{i w}} \int_{-\infty}^{S_{i w}-x}\left(S_{i w}-x-u\right) f_{\text {iv }}(x) f_{\text {iw }}(u) d u d x / 2 T\right.
$$

$x$ is the error of inventory goods in the same logistics environment every day. ${ }^{u}$ is a real commodity inventory consumption, $f_{i w}(x) f_{i w}(u)$ is the actual inventory digestion and inventory error in iw environment in the current logistics transportation environment. 
In T days, sales cost of product i generated in commodity distribution center of different regions, in the same logistics environment is the product of unit holding cost ${ }^{h_{i w}}$ with everyday's average inventory ${ }^{I_{i w}}$ and T days, then the cost of sales is ${ }^{H C_{i w}}$ :

$$
H C_{i w}=2 T h_{i w} I_{i w}
$$

Expected number of stockout of shortage products i in the distribution center of good logistics area is:

$$
E S_{i w}=\int_{-\infty}^{S_{i v}-\infty} \int_{S_{i w}}\left(u-\left(S_{i w}-x\right)\right) f_{i w}(u) f_{i w}(x) d u d x
$$

In $\mathrm{T}$ days, similar logistics transportation environment, the service level of product $\mathrm{i}$ in distribution center of special regional commodity is $E S L_{i w}$

$$
E S L_{i w}=1-\frac{E S_{i w}}{2 \mu_{i w}+E S_{i w}}
$$

To obtain in $\mathrm{T}$ days, similar logistics transportation environment, in the distribution center of good and bad logistics region, the average net income of sales production i (sales revenue minus the procurement cost and the sales loss) is:

$$
S V_{i w}=\left(W_{i}-W_{i}^{\prime}\right)\left(2 \mu_{i w}-E S_{i w}\right)
$$

Among them, $W_{i}$ is the sales revenue, $W^{\prime}$ is the cost of procurement. after getting each index, it can calculate the total profit model in special commodity distribution center in $\mathrm{T}$ days , in the same logistics effect environment, also is the logistics lines after artificially optimization (where, ${ }^{T P_{w}}$ is the optimizing function in similar optimization logistics transportation condition.)

$$
K=T P_{w}\left(I_{i w}, H C_{\text {iw }}, E S_{\text {iw }}, E S L_{\text {iv }}, S V_{\text {iw }}\right)
$$

$\mathrm{K}$ is the optimal value of the model in a similar optimization logistics transportation environment, it is the optimal value of sales of commodities.

Through the above method, it can obtain commodity sales profit model in special area under logistics lines in different situations, and then the commodity sales profits are made optimization analysis, finally ensuring in underdeveloped logistics regions, commodity distribution profits is in the maximum, to promote the development of commodity economy of special areas.

\section{Experimental analysis}

In order to validate the model in this paper, it needs to make the related experiments analysis, to compare the levels of distribution of different commodities and market share rate in different logistics area in the proposed model and traditional model, the results are shown in table 1 and table 2.

Table 1 regional commercial distribution level of different models (\%)

\begin{tabular}{clllllll}
\hline \multirow{2}{*}{ Market j j } & \multicolumn{2}{l}{ Traditional model } & \multicolumn{2}{l}{ The proposed model } \\
\cline { 2 - 7 } & $\begin{array}{lllllll}\text { Region } \\
\end{array}$ & 2 & 2 & 3 & 1 & 2 & Region \\
\hline \multirow{2}{*}{ Product i } & 58 & 60 & 62 & 75 & 80 & 85 \\
\cline { 2 - 7 } & 62 & 66 & 69 & 78 & 83 & 86 \\
\hline
\end{tabular}


Table 2 regional commodity distribution market share of different models (\%)

\begin{tabular}{lllllll}
\hline \multirow{2}{*}{ Market j } & \multicolumn{2}{l}{ Traditional model } & \multicolumn{3}{l}{ The proposed model } \\
\cline { 2 - 7 } & $\begin{array}{l}\text { Region } \\
\text { Region }\end{array}$ & 2 & Region 3 $\begin{array}{l}\text { Region } \\
1\end{array}$ & $\begin{array}{l}\text { Region } \\
2\end{array}$ & Region 3 \\
\hline \multirow{3}{*}{ Product i } & 16 & 18 & 19.5 & 18 & 22 & 25 \\
\cline { 2 - 7 } & 17 & 18.5 & 21 & 19 & 23 & 26 \\
\cline { 2 - 7 } & 17.5 & 19 & 22 & 19.5 & 24.5 & 28 \\
\hline
\end{tabular}

The analysis of table 1 and table 2, it can be seen that the levels of distribution of different commodities and market share rate in different logistics area in this paper's model are superior to that of traditional model, showing that this model is effective in optimization of commodity distribution performance in special area. Similarly, it can obtain the increase of commodity profit in the model of this paper, described in table 3.

Table 3 the commercial profit growth of the proposed model

\begin{tabular}{lcll}
\hline Item & Region 1 Region 2 & Region 3 \\
\hline Current obtained profit & 139.93 & 142.44 & 155.68 \\
\hline Targeted profit & 146.55 & 148.67 & 162.87 \\
\hline $\begin{array}{l}\text { Available profit of the } \\
\text { proposed model }\end{array}$ & 144.83 & 148.48 & 164.85 \\
\hline \begin{tabular}{l} 
Growth rate \\
\hline
\end{tabular} & 4.58 & 5.65 & 7.18 \\
\hline
\end{tabular}

The analysis of table 3, can show in region 1 3, the increasing rate of commodity market profit rate is respectively $4.58 \%, 5.65 \%$ and $7.18 \%$, all of them reached $5 \%$, the profit objectives, showing that this model can improve commodity distribution profits of the special area, which has important application value.

In order to further analyze the superiority of this model, the same commodity profit growth rate under the proposed model and traditional model in 10 special areas are compared, and the results are as shown in figure 1 :

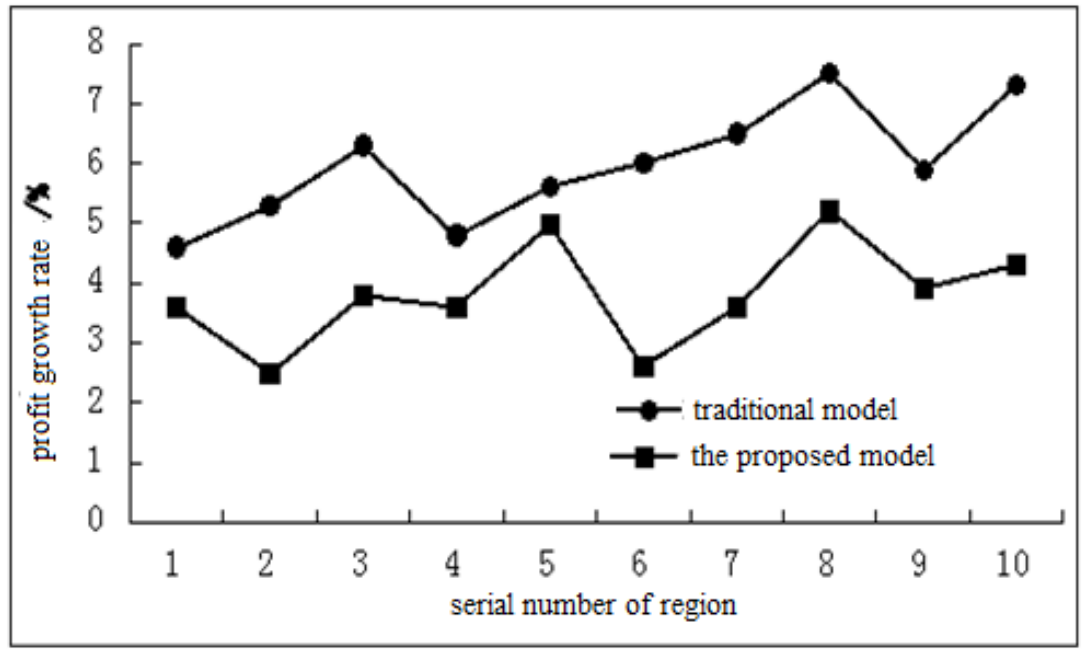

Figure 1 comparison of commercial profit growth rate of different models

As it can be seen from Figure 1, in the proposed model the profit growth rate of commodity distribution is higher than that of the traditional model, and all the profit growth rate are higher than $5 \%$ which is the target profit; while in the traditional model, only two regional profit growth rate reached 5\% of the profit target. the proposed model are more close to the real situation, demonstrating this model for, goods distribution has stronger positive effect in different logistics transport conditions, which greatly improved the regional commercial profit, and get satisfactory results. 


\section{Conclusions}

In this paper, a distribution model of product's profit based on improved max min ant algorithm is proposed. Using improved max min ant method obtain the relationship between the convenient degree of logistics supply chain and the sale of goods, and the results are input to commodity's distribution profit model to make analysis. The distribution situation of goods in special areas is made reasonable analysis, to ensure the maximized regional commodity sales profit. Experimental results show that in the proposed model, the commodity's distribution level, market share rate and profit growth rate is better than that of the traditional model, it has a higher application value.

\section{References}

[1] Wang Yingjun, Gao Junjun. Optimization and simulation of supply chain distribution system [J]. Journal of management science, 2002, 5:79-84.

[2]Philip. Kotler. Marketing management: analysis, planning and control [M]. Shanghai: Shanghai people's publishing house, 1990

[3] Gao Junjun, Wang Yingjun, Guo Yajun. The minimum cost model of a distribution system with uncertain demand $[\mathrm{J}]$. Journal of Northeastern University (NATURAL SCIENCE EDITION), 2002, 1:87-90.

[4] Guo Xionghuang, Li Jun. Optimization of vehicle dispatching [M]. Chengdu: Chengdu University of Science and Technology press, 1994

[5] Liu Zhishuo, Shen Jinsheng. An Adaptive Ant Colony Algorithm for Vehicle Routing Problem Based on the Evenness of Solution [J]. Journal of system simulation, 2005, 17 (5) 66-69

[6] Zhang Xuemin, Zhang hang. Research on the problem of shortest path based on improved ant colony algorithm [J]. Control theory and applications, 2009, 28 (6): 4-6. 